\title{
Overview of Results from the Asian Seas International Acoustics Experiment in the East China Sea
}

\author{
Peter H. Dahl, Renhe Zhang, James H. Miller, Louis R. Bartek, Zhauhui Peng, Steven R. Ramp, Ji-Xun Zhou, \\ Ching-Sang Chiu, James F. Lynch, Senior Member, IEEE, Jeffrey A. Simmen, and Robert C. Spindel
}

\begin{abstract}
The Asian Seas International Acoustics Experiment (ASIAEX) included two major field programs, one in the South China Sea and the other in the East China Sea (ECS). This paper presents an overview of research results from ASIAEX ECS conducted between May 28 and June 9, 2001. The primary emphasis of the field program was shallow-water acoustic propagation, focused on boundary interaction and geoacoustic inversion. The study area's central point was located at $29^{\circ} 40.67^{\prime} \mathrm{N}, 126^{\circ}$ 49.39'E, which is situated $500 \mathrm{~km}$ east of the Chinese coastline off Shanghai. The acoustic and supporting environmental measurements are summarized, along with research results to date, and references to papers addressing specific issues in more detail are given.
\end{abstract}

Index Terms-Propagation, reverberation, seabed, sea surface, shallow water acoustics.

\section{INTRODUCTION}

$\mathbf{T}$ HE CENTERPIECE of the Asian Seas International Acoustics Experiment (ASIAEX) consisted of two major field programs conducted in the spring of 2001, one in the South China Sea (see Lynch et al. [1]) and the other in the East China Sea (ECS). The intent of this paper is to provide an overview of research results to date of ASIAEX ECS, conducted primarily under the auspices of the U.S. Office of Naval Research and the Natural Science Foundation of China. The U.S., Chinese, and Korean research organizations involved in the 2001 ECS field program are listed in Table I.

The primary goals of ASIAEX ECS were to: 1) identify and elucidate properties of shallow-water boundaries governing propagation and reverberation in the ECS, such as sediment inhomogeniety, sediment roughness, and sea surface roughness and 2) establish a geoacoustic description for the ECS seabed, based on complementary approaches to inverting acoustic propagation and reverberation measurements made in the $O(10-10000) \mathrm{Hz}$ frequency range. The ECS study area, jointly approved by the State Oceanic Administration, People's Republic of China, and the Japanese Ministry of Foreign Affairs, was a box defined by $28^{\circ}$ to $30^{\circ} \mathrm{N}$ and $126^{\circ} 30^{\circ}$ to $128^{\circ} \mathrm{E}$.

Leading up to the 2001 primary study in the ECS was a pilot study conducted in the spring of 2000 from the U.S. R/V Revelle (see Ramp et al. [2]), aimed at obtaining environmental data within this boxed area to support the acoustics experiments planned for 2001 (see Table II for the list of organizations involved in the 2000 pilot study). Information on the ECS seabed

This paper is part of the Guest Editorial for the Special Issue on Science and Engineering Advances in Exploring the Asian Marginal Seas.

Digital Object Identifier 10.1109/JOE.2005.843159
TABLE I

RESEARCH INSTITUTIONS INVOLVED IN THE 2001 ASIAEX EAST CHINA SEA PRIMARY STUdY

\begin{tabular}{c|c}
\hline INSTITUTION & Country \\
\hline $\begin{array}{c}\text { Applied Physics Laboratory, University of } \\
\text { Washington }\end{array}$ & USA \\
\hline $\begin{array}{c}\text { Dalian Scientific Test \& Control Technology } \\
\text { Institute }\end{array}$ & CHINA \\
\hline $\begin{array}{c}\text { Georgia Institute of Technology } \\
\text { Institute }\end{array}$ & USA \\
\hline $\begin{array}{c}\text { Hangzhou Applied Acoustics Research } \\
\text { Harbin Engineering University }\end{array}$ & CHINA \\
\hline Institute of Acoustics, Beijing & CHINA \\
\hline $\begin{array}{c}\text { Korean Ocean Research and Development } \\
\text { Institute }\end{array}$ & KOREA \\
\hline Marine Physical Laboratory, Scripps & USA \\
\hline National Taiwan University & TAIWAN, CHINA \\
\hline $\begin{array}{c}\text { Northwestern PolyTechnical University, } \\
\text { Xi'an }\end{array}$ & CHINA \\
\hline Ocean University of Qingdao & CHINA \\
\hline $\begin{array}{c}\text { South China Sea Institute of Oceanology, } \\
\text { Guangzhou }\end{array}$ & CHINA \\
\hline University of Rhode Island & USA \\
\hline
\end{tabular}

TABLE II

RESEARCH INSTITUTIONS INVOLVED IN THE 2000 ASIAEX ECS PILOT STUdY

\begin{tabular}{c|c}
\hline INSTITUTION & Country \\
\hline Florida Atlantic University & USA \\
\hline Marine Physical Laboratory, Scripps & USA \\
\hline Naval Postgraduate School & USA \\
\hline University of North Carolina & USA \\
\hline University of Rhode Island & USA \\
\hline Woods Hole Oceanographic Institution & USA \\
\hline
\end{tabular}

and subbottom structure derived from this earlier study (see Miller et al. [3]) was used to select the final study area for the primary experiment in 2001, involving the U.S. R/V Melville and the Chinese R/Vs Shi Yan 2 and Shi Yan 3 (Fig. 1). The center point of this area, located at $29^{\circ} 40.67^{\prime} \mathrm{N}$ and $126^{\circ} 49.39^{\prime} \mathrm{E}$, is referred to in several papers in this special issue as position $\mathrm{M}$ and is located in the northwest corner of the approved box about $500 \mathrm{~km}$ east of the Chinese coastline off Shanghai. Position M (Fig. 1) became the designated center of a 30-km-radius circular transect over which broadband, explosive sound sources were deployed for the propagation and reverberation experiments in 2001. (These acoustic sources are often referred to in Chinese technical literature as Wide Band Source (WBS), an acronym for wide band source that is used in several papers in this issue.) 


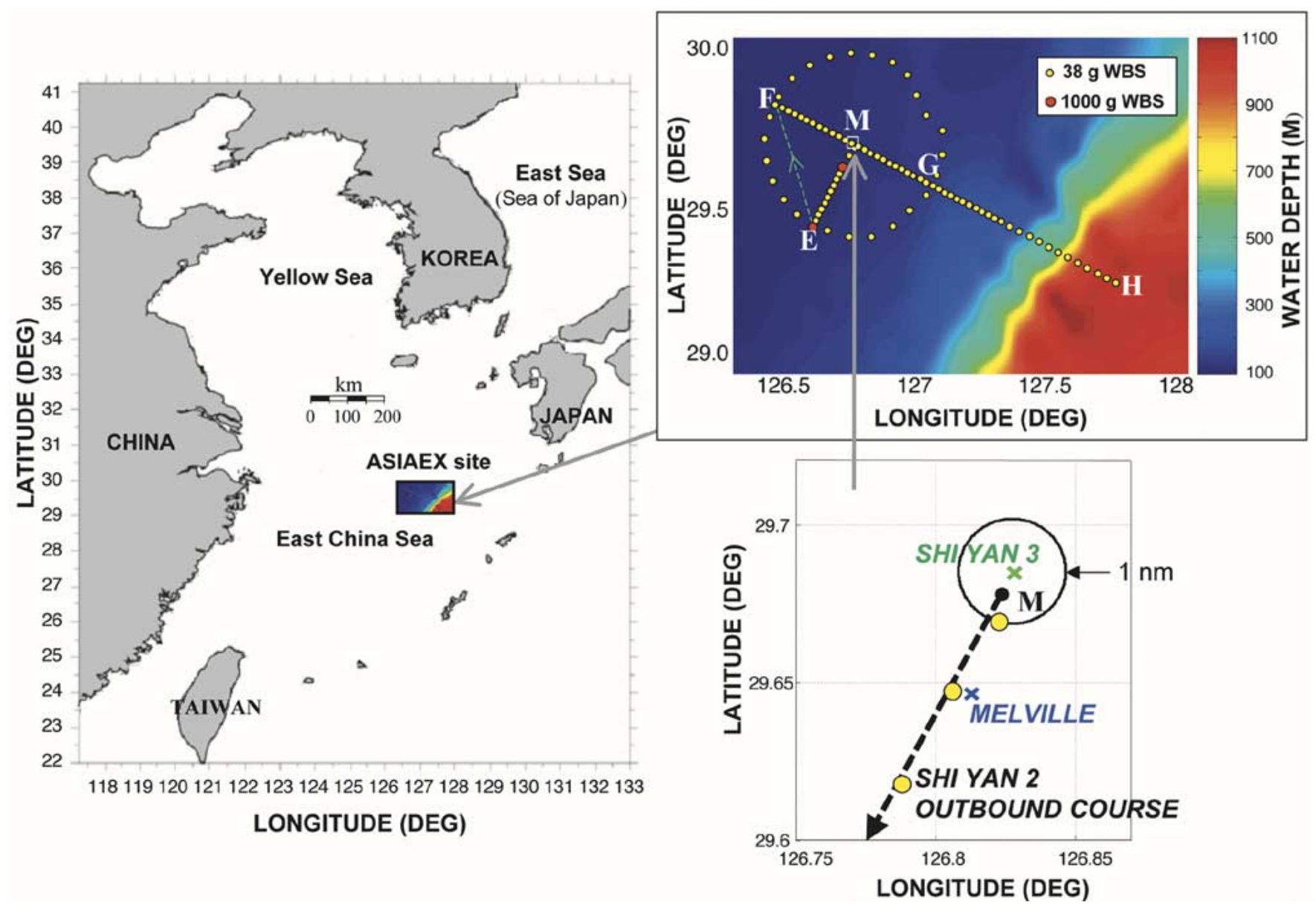

Fig. 1. Location of the ASIAEX ECS experimental site. Clockwise from left: large-scale view reducing to small scale (lower right) showing positions of the R/V Shi Yan 3 and R/V Melville near position M and the outbound course of the R/V Shi Yan 2. Upper right panel shows the location of explosive sources (WBS) deployed from the Shi Yan 2. Between waypoints F-G and M-E, these sources (38-g) are deployed approximately every $2 \mathrm{~km}$. Yellow circles in lower right panel show positions of the initial three 38-g source deployments by the Shi Yan 2.

The final study area and position $\mathrm{M}$ were also selected because the bathymetry there was relatively simple and characterized by parallel isobaths oriented southwest to northeast. The water depth was $105 \mathrm{~m} \pm 3 \mathrm{~m}$ for radials extending out approximately $10 \mathrm{~km}$ from position $\mathrm{M}$ in any direction. Further motivation for selecting this site was its reduced water column variability, desirable in view of the experimental emphasis on boundary interaction. The variability was reduced because of the appreciable standoff distance from the shelf break where the north wall of the Kuroshio resides. Linear and nonlinear internal waves were observed during both 2000 and 2001, but they were neither as frequent nor as energetic as the waves observed in the South China Sea [2].

The area encompassed by the $30-\mathrm{km}$ radius circle in Fig. 1, known as the large-scale ECS experimental site, was the primary site for low-frequency, $O(10-1000) \mathrm{Hz}$, propagation and reverberation studies. A subset area of approximately $10 \mathrm{~km}^{2}$, centered at position $\mathrm{M}$, was the site for mid-to-high frequency, $O(1-10) \mathrm{kHz}$, studies. (Table III summarizes all the major ECS ocean acoustic studies, classified here as either narrow band if the acoustic measurement bandwidth was less than one octave or as broadband if the bandwidth was greater than one octave.) The approach of embedding mid-to-high-frequency acoustic experiments within an area where low-frequency experiments were also conducted served two purposes. The first was to more efficiently allocate limited resources for seabed sampling; for example, the area immediately surrounding position $\mathrm{M}$ received substantially more emphasis insofar as coring [3] and measurements of fine-scale bottom relief [4]. The second was to conduct multiple-frequency geoacoustic inversions on the same area of seabed. That is, the inner region about position $\mathrm{M}$ was studied using a wide range of frequencies, $O(10-10000) \mathrm{Hz}$. The lower end of this band yielded low-resolution but deep, $O(10 \mathrm{~m})$, information about the sediment; the higher end of this band yielded little or no information on the deep sediments, but provided better resolution on upper sediment structure (e.g., layering). A key objective of ASIAEX ECS was to fuse inversion results from such frequency-complementary acoustic experiments. This was achievable at position $\mathrm{M}$, although the process of doing so continues at this writing.

The remainder of this paper provides an overview of results of the environmental characterization (Section II) and results of analysis of ocean acoustic experiments to date (Section III), along with references to papers addressing specific issues in more detail. 
TABLE III

CHRONOLOGY OF MAJOR OCEAN ACOUSTIC EXPERIMENTS FOR ASIAEX ECS CONDUCTED BY TEAMS FROM THE U.S. AND CHINA (DATES AND TIMES IN UTC.) EXPERIMENTS ARE CLASSIFIED AS EITHER NARROWBAND (NB) IF THE ACOUSTIC MEASUREMENT BANDWIDTH IS LESS THAN ONE OCTAVE OR BROADBAND (BB) IF BANDWIDTH IS GREATER THAN ONE OCTAVE. THE NOMINAL CENTER FREQUENCIES (FOR NB) OR FREQUENCY RANGE (FOR BB) OF A PARTICULAR EXPERIMENT IS GIVEN IN BRACKETS

\begin{tabular}{|c|c|c|c|c|c|c|c|c|c|c|}
\hline & \begin{tabular}{|l|}
30 May \\
JD 150
\end{tabular} & $\begin{array}{l}31 \text { May } \\
\text { JD } 151\end{array}$ & \begin{tabular}{|l}
1 June \\
JD 152
\end{tabular} & \begin{tabular}{|l|}
2 June \\
JD 153
\end{tabular} & \begin{tabular}{|l|} 
3 June \\
JD 154
\end{tabular} & \begin{tabular}{|l|}
4 June \\
JD 155
\end{tabular} & \begin{tabular}{|l|}
5 June \\
JD 156
\end{tabular} & $\begin{array}{l}6 \text { June } \\
\text { JD } 157\end{array}$ & \begin{tabular}{|l|}
7 June \\
JD 158
\end{tabular} & \begin{tabular}{|l}
8 June \\
JD 159
\end{tabular} \\
\hline $\begin{array}{l}\mathrm{NB}[3.5 \mathrm{kHz}] \\
\text { Bottom Reverberation }\end{array}$ & | & & & & & & & & & \\
\hline $\begin{array}{l}\text { NB [2-20 kHz] } \\
\text { Sea Surface Forward } \\
\text { Scattering, } \\
\text { Propagation }(<1 \mathrm{~km})\end{array}$ & & & & & & & & & & \\
\hline $\begin{array}{c}\text { NB [850 Hz] } \\
\text { Bottom Reverberation }\end{array}$ & & & & & & & & & & \\
\hline $\begin{array}{c}\mathrm{BB}[50-1000 \mathrm{~Hz}] \\
\text { Total Reverberation }\end{array}$ & & & & & & & & & & \\
\hline $\begin{array}{c}\text { BB [50-1000 Hz] } \\
\text { Propagation, Sediment } \\
\text { Inversion } \\
(1-100 \mathrm{~km})\end{array}$ & & & & & & & & & & \\
\hline $\begin{array}{c}\mathrm{NB}[3 \mathrm{kHz}] \\
\text { Bottom Reverberation }\end{array}$ & & & & & & & & & & \\
\hline $\begin{array}{l}\text { NB [630 Hz] } \\
\text { BB [50-1000 Hz] } \\
\text { Propagation } \\
\text { (5-40 km) }\end{array}$ & & & & & & & & & & \\
\hline $\begin{array}{c}\mathrm{NB}[100-1000 \mathrm{~Hz}] \\
{[1.6-4.4 \mathrm{kHz}]} \\
\text { Towed Source Propagation } \\
\text { (5 km transect) }\end{array}$ & & & & & & & & & & \\
\hline
\end{tabular}

\section{OVERVIEW OF RESULTS OF ENVIRONMENTAL CHARACTERIZATION}

\section{A. Seabed}

Several measurement techniques were used to determine the properties of sediments in the ECS, as described by Miller et al. [3]. Within the 30-km-radius circle (Fig. 1), 21 gravity cores were collected from the U.S. R/V Revelle as part of the environmental assessment in 2000; additional gravity cores were collected during 2001 from the R/V Shi Yan 3 during the main experiment and two months later the Taiwanese R/V Ocean Researcher 2 returned to the experimental site to collect 30 piston cores. The gravity cores and the piston cores obtained samples $25 \mathrm{~cm}$ and $2 \mathrm{~m}$ deep, respectively. Analysis [3] of the Revelle coring set suggests a compressional wave speed in the surface sediment layer varying from near $1600 \mathrm{~m} / \mathrm{s}$ at core stations located in the northwest quadrant of the $30-\mathrm{km}$ circle to near 1650 $\mathrm{m} / \mathrm{s}$ at some stations in the vicinity of the circle's center. The spatial distribution of mean grain size (see [3]) derived from the Ocean Researcher 2 coring set (Fig. 2) points to variation on scales much smaller than that originally depicted by an historical mud-sand boundary discussed in [3]. Subbottom profiling using water-gun and chirp sonars was conducted on the Revelle cruise; these measurements indicate that the subbottom structure at the experiment site consists of a thin veneer of sediment of variable thickness directly beneath the sea floor. Near position $\mathrm{M}$ the sediment layer is about $1 \mathrm{~m}$ thick. Below this layer, there is sediment with relatively uniform acoustic attributes.

The sediment porosity and fine-scale relief measurements (within a 4-m measurement aperture) put the seabed root-mean-square $(\mathrm{rms})$ relief at $0.5 \mathrm{~cm}$ in the vicinity of position M [4]. A frozen video image (Fig. 3) taken from the

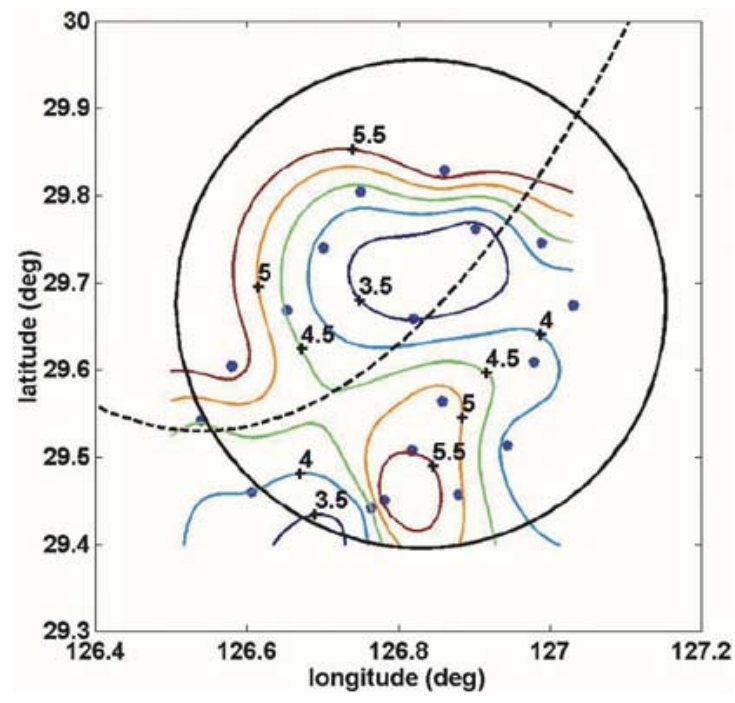

Fig. 2. Contours of the spatial distribution of mean grain size in phi units, based on the coring locations shown by the blue dots (figure adapted from [3]). Phi units are defined as minus $\log _{2}$ of the grain diameter in millimeters; lower phi values indicate more sandy-like sediments and higher phi values indicate more mud-and-sand-like sediments. The circle has radius $30 \mathrm{~km}$ with position $\mathrm{M}$ at the center; the dashed line is the historical mud-sand boundary discussed in Miller et al. [3] with sand to the southeast and mud-sand to the northwest.

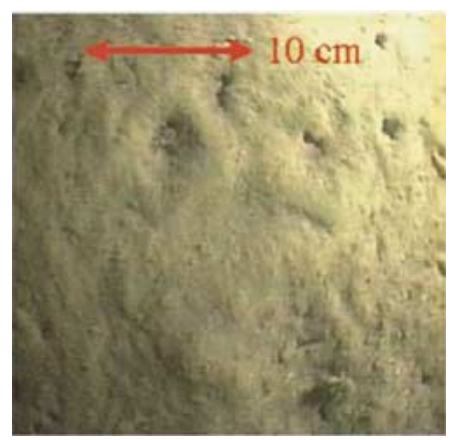

Fig. 3. Frozen video image (courtesy of D. Tang, Applied Physics Laboratory, University of Washington, Seattle) of the seabed taken near position M, showing an example of indentations from bottom-dwelling organisms that are postulated to be responsible for the small-scale relief.

instrument (see [4]) shows an example of the indentations from bottom-dwelling organisms that are postulated to be responsible for the fine-scale relief. Tang [4] has developed a bioturbation model that reproduces the observed mean roughness spectrum. These measurements are necessarily a high-pass filtering of relief and do not capture variability at length scales greater than about $2 \mathrm{~m}$, but are essential for modeling acoustic backscatter in a mid-frequency $(3-4 \mathrm{kHz})$ range. Future work will combine this data with chirp-sonar measurements made in 2000 and 2001. Possible contributors to large-scale relief are trawl marks, observed by side-scan sonar in 2000; however, the degree to which bottom trawling contributed to bottom relief during the 2001 study is unclear.

\section{B. Volume}

During the 2001 experiment, sound speed in the water column was measured routinely and at varying intervals by conductivity-temperature-depth (CTD) casts from the Melville 

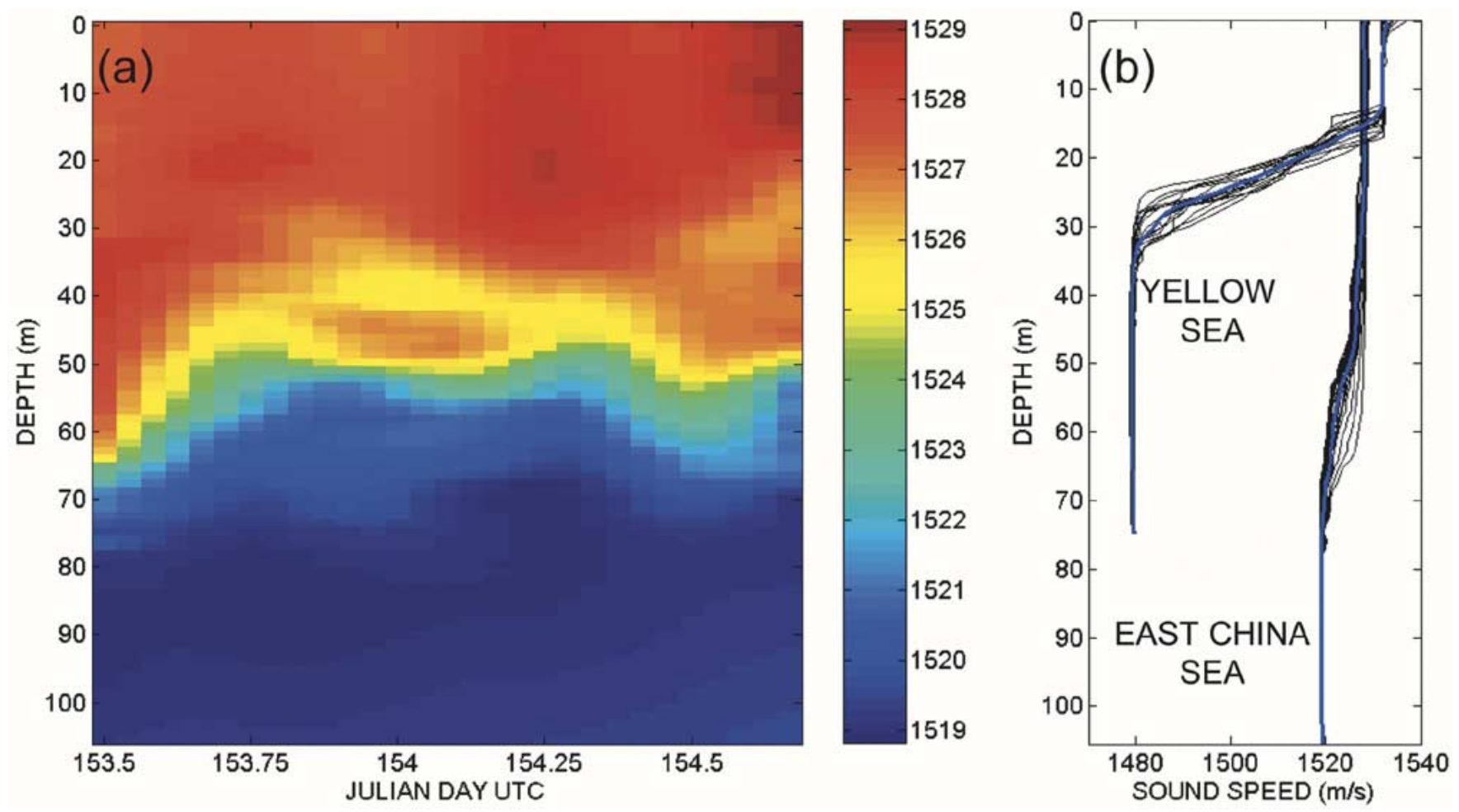

Fig. 4. (a) Example of the time variation in the sound-speed vertical structure for the ECS taken at position M, starting UTC 1200 on June 2 (Julian day 153), as measured by CTD. (b) A 24-h average of the data in (a), compared with an equivalent average of sound speed versus depth taken in the Yellow Sea in August 1996. The thick, blue line is the 24-h average and thin, black lines are individual CTD measurements made hourly.

and the Shi Yan 3. Typical time variation in the sound-speed profile for the ECS in late spring [Fig. 4(a)] shows the dominant component of the variance linked to the semidiurnal (M2) internal tide oscillation of the thermocline. (Associated baratropic tidal current magnitudes were approximately $40 \mathrm{~cm} / \mathrm{s}$ and maximum surface elevation changes were approximately 100 $\mathrm{cm}$.) A comparison of a 24-h average of this data [Fig. 4(b)] with an equivalent average of the sound-speed profile taken in the Yellow Sea in August 1996 [5] shows that the late-spring thermocline in the ECS is truly weak when compared with the late-summer thermocline in the Yellow Sea. The acoustic implication is that the sea surface should have a greater influence on propagation and reverberation in the ECS than in the Yellow Sea. More detail and discussion on the salinity and temperature profiles and the internal wave characteristics of the ECS are presented in Ramp et al. [2] and Yang et al. [6].

\section{Sea Surface}

Between May 29 and June 7, 2001, wind speed varied from $1-13 \mathrm{~m} / \mathrm{s}$ and the rms wave height varied between about $0.1-0.6 \mathrm{~m}$, providing a wide range of sea state conditions for the ASIAEX ocean acoustic experiments conducted in the ECS (Fig. 5). In particular, three acoustic experiments have been subject to closer examination in regard to the impact of concurrent sea surface conditions. Sea state conditions for the WBS detonations on June 3 at 0109, intended primarily for broadband measurements of seabed reverberation, were characterized by an rms wave height and wind speed of $0.1 \mathrm{~m}$ and $3 \mathrm{~m} / \mathrm{s}$, respectively; for the measurements made on June 5 at 0520 , the rms wave height and wind speed had increased to
$0.34 \mathrm{~m}$ and $9 \mathrm{~m} / \mathrm{s}$, respectively. The $24-\mathrm{h}$ broadband propagation experiment involving WBS deployments from the Shi Yan 2 began in relatively calm conditions, but ended in conditions characterized by rms wave height and wind speed of $0.6 \mathrm{~m}$ and $11 \mathrm{~m} / \mathrm{s}$, respectively. Finally, the two, 24-h narrow-band measurements, designed specifically to capture acoustic effects of changing sea state conditions, were also successful in sampling a large range of sea state conditions. Time windows for these experiments are indicated in Fig. 5.

\section{OVERVIEW OF RESULTS OF OCEAN ACOUSTIC EXPERIMENTS}

Considerable progress has been made toward establishing a geoacoustic description of the ECS seabed [3], [7]-[15], based on complementary approaches to inversion. It is important to keep the diversity of acoustic field measurements in mind, representing one-way propagation and two-way reverberation, made at frequencies ranging from $O(10-10000) \mathrm{Hz}$, that have been utilized for these geoacoustic inversions. Such measurements interrogate the seabed in fundamentally different ways. Furthermore, the different approaches to geoacoustic inversion embodied by the degree of parsimony inherent in the inversion forward model, e.g., a half-space representation for the seabed as in [10]-[13], [15] versus a structured seabed representation that includes layers and gradients as in [3], [7]-[9], [14], invariably lead to seemingly different inversion goals and subsequent geoacoustic models for the seabed. (A lucid clarification concerning the basis of differing inversion goals is given in [16].) Still, a fair degree of consistency has emerged. For example, the range of inverted sound speeds corresponding to the water-sediment 

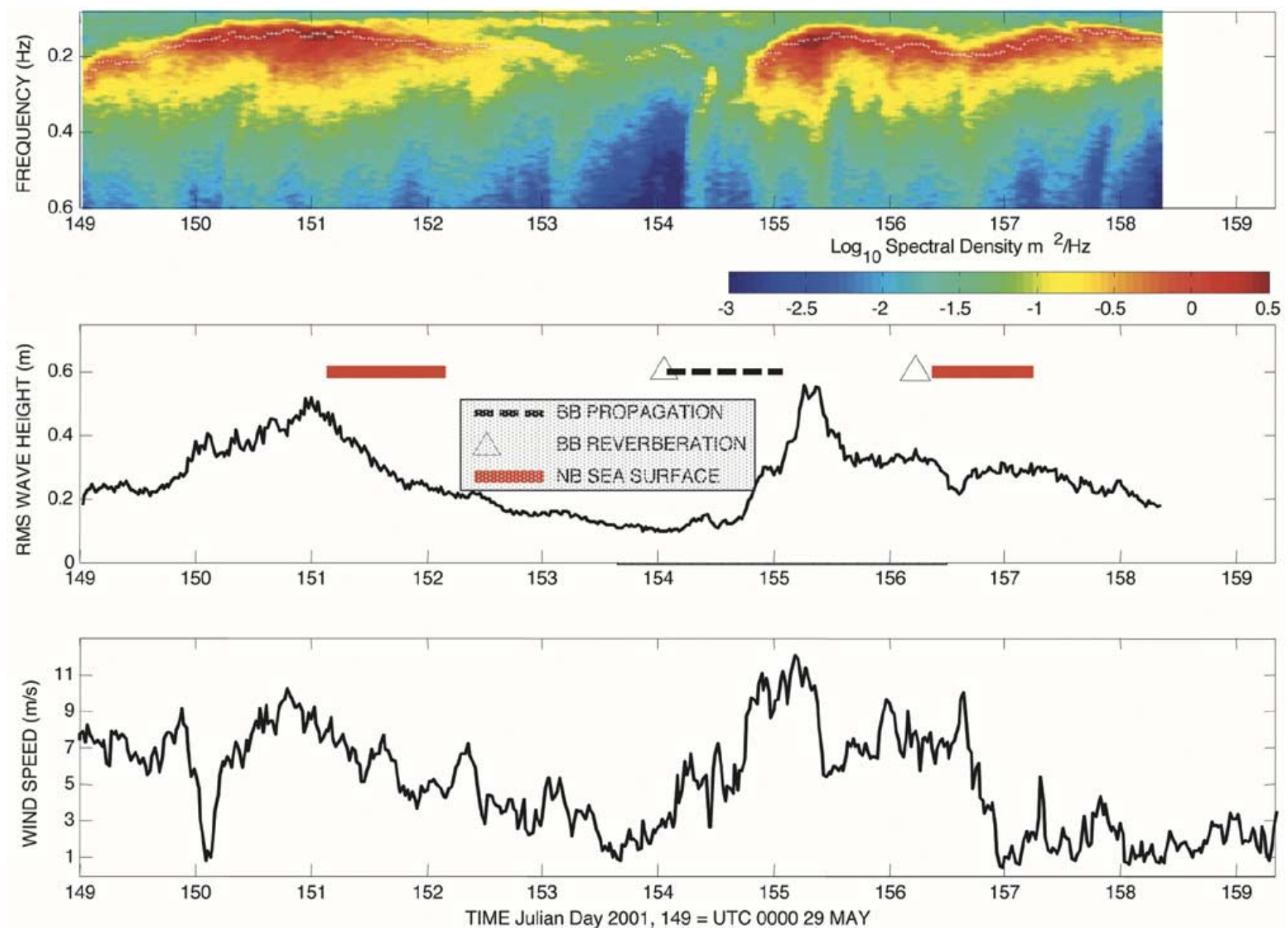

Fig. 5. Time history of the wind and sea surface waves made during ASIAEX ECS. Wind speed was measured from the R/V Melville's IMET station and wave data were measured with a directional wave buoy positioned approximately $500 \mathrm{~m}$ from the Melville. (Top) Contour of directional averaged wave spectra (see [22] for an example of directional wave data), taken every $0.5 \mathrm{~h}$, with white dots showing location of peak frequency. (Middle) Time series of rms waveheight, along with approximate time windows for three acoustic experiments. (Bottom) Time series of wind speed; note that wind-speed data continue slightly beyond the wave buoy recovery time.

interface is $1557-1643 \mathrm{~m} / \mathrm{s}$; at a depth of $0.5 \mathrm{~m}$, this range is $1590-1643 \mathrm{~m} / \mathrm{s}$ and at a depth of $1 \mathrm{~m}$, it is $1600-1650 \mathrm{~m} / \mathrm{s}$. This general increase in compressional wave speed with depth into the seabed is consistent with the results of Zhou et al. [11], who invert reverberation measurements made in the frequency range $100-1500 \mathrm{~Hz}$ based on a half-space representation for the seabed. They obtained an equivalent half-space sound speed that increased with decreasing frequency and their results illustrate how the resolution scales inversely with frequency. For example, the minimum inverted sound speed for the water-sediment interface, $1557 \mathrm{~m} / \mathrm{s}$, was obtained with $O(10) \mathrm{kHz}$ measurements [7].

In regard to sediment attenuation in the ECS, the ASIAEX results (summarized in Fig. 6) display both linear and nonlinear trends for attenuation as a function of frequency in the $50-500-\mathrm{Hz}$ frequency range. At this writing, these results point to more questions than answers; clearly, understanding and reconciling the frequency dependence poses a challenge for follow-up analysis of ASIAEX data or for future experiments conducted in this same region. This includes the relative importance of shear wave conversion as a loss mechanism for lower frequencies. Furthermore, it will be effective in future work to assign geoacoustic estimates obtained at higher frequencies to the region near the water-sediment interface and geoacoustic estimates obtained at lower frequencies to deeper sediment regions, for a geoacoustic model for the ECS that is robust over a broad frequency range.

From inversion benchmark studies [17], absolute (calibrated) transmission loss has been shown to be an effective metric with which to quantify and compare the performance of inversion results based on different methodologies. In this regard, the transmission loss estimates for ASIAEX ECS described in [12], derived from the propagation measurements made along the three, 30-km length radials EM, FM, and GM (Fig. 1), will be particularly valuable for future benchmarking. (A companion analysis utilizing the same propagation data set [18] demonstrates improvement in the matched-field source localization performance upon inclusion of bottom slope information.) Fig. 7 displays a subset of the transmission loss estimates (along the GM radial) expressed in decibels re $1 \mathrm{~m}$ versus range for third-octave center frequencies between 40-2500 Hz.

Modeling and interpretation of ASIAEX bottom reverberation measurements is in large part dependent upon the seabed characterization and such data also requires a substantial 


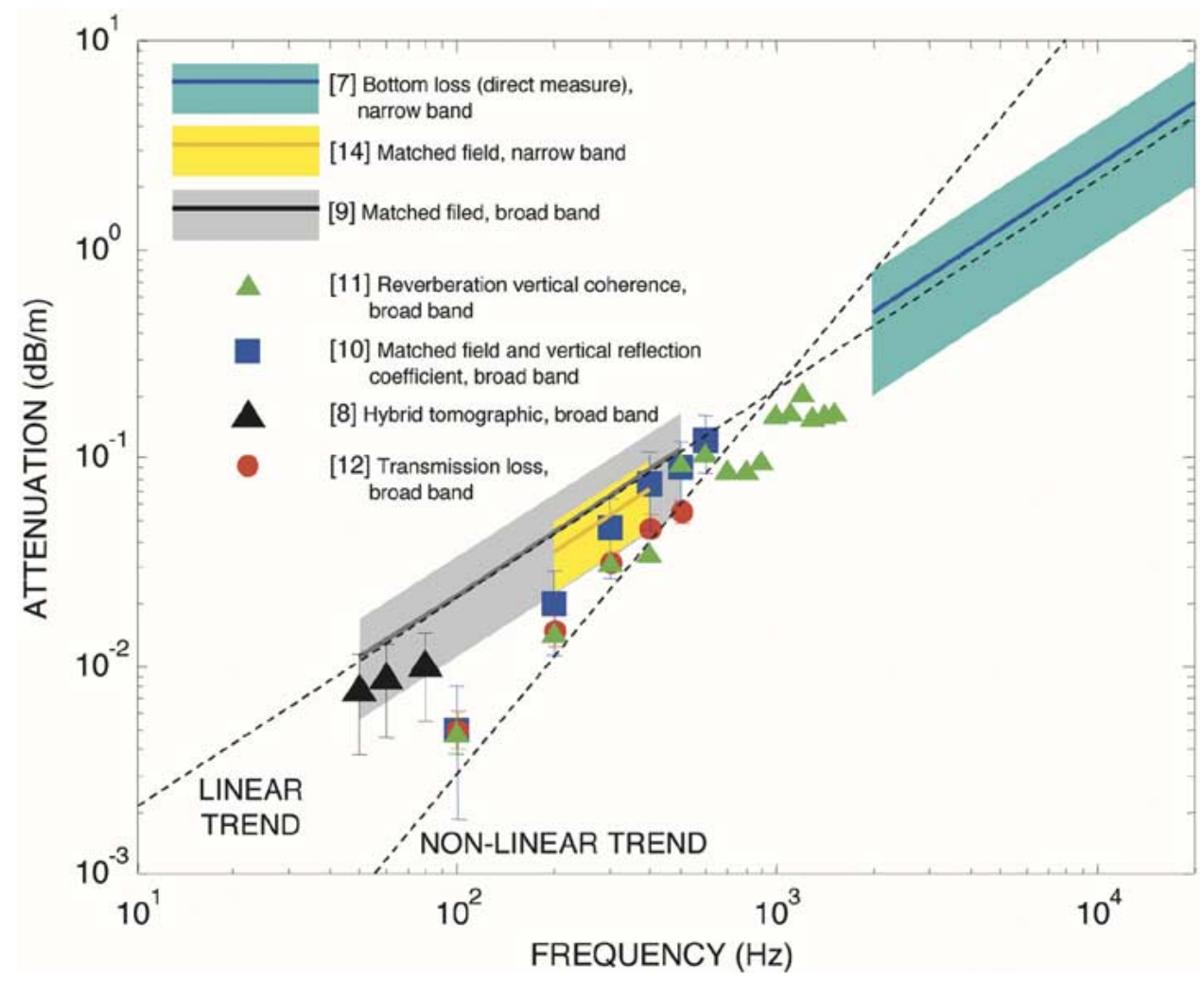

Fig. 6. Results of inversion for sediment attenuation in the ECS. The legend gives a brief description of the inversion approach, with broadband and narrowband defined as in Table III and Section I; reference numbers refer to this paper.

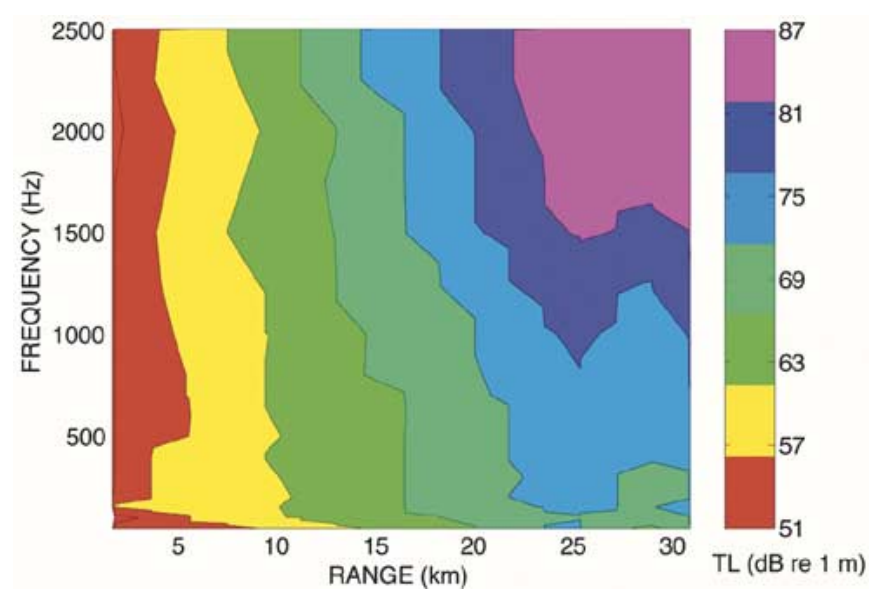

Fig. 7. Transmission loss in decibels re $1 \mathrm{~m}$ as a function of range from position $\mathrm{M}$ along track MG (Fig. 1) and 1/3-octave bandwidth center frequency. Both source and receiver depth are $50 \mathrm{~m}$. Data from [12].

degree of processing, interpretation, and modeling (some of the results of which are reported in this issue). Thus far, emerging results [19] have established a link between reverberation from the seabed and fine-scale relief [4] (rather than subbottom inhomogenities) for bottom reverberation in the $O(1-10) \mathrm{kHz}$ frequency range.

In terms of the role of sea state in governing the strength and coherence of shallow-water acoustic propagation and scattering over frequencies of $O(100-10000) \mathrm{Hz}$, the following results have emerged thus far. The two 24-h length measurement periods of forward scattering from the sea surface yielded a large data set with which to evaluate energy loss associated with wind-speed-dependent bubbles. Results in [20] show how this loss varies with wind speed and a model is presented that agrees well with ASIAEX data and other archival measurements. This dependence on wind speed is not clearly evident with the ASIAEX data alone; however, when it is combined with the archival data, the dependence is clear (Fig. 8). In contrast to coherent surface loss, incoherent loss (or energy loss in Fig. 8) was small and difficult to precisely measure against ordinary statistical fluctuation, for wind speeds up to about 8 $\mathrm{m} / \mathrm{s}$. Fig. 8 also illustrates for the ASIAEX conditions and measurement geometry, the poor correlation between energy loss and the Rayleigh parameter $\chi=2 k H \sin (\theta)$, where $k$ is wave number, $H$ is rms wave height, and $\theta$ is the nominal sea surface grazing angle. This is expected given that near-surface bubble concentration correlates well with wind speed and poorly with wave height [21]. These results are significant because, in some propagation schemes, coherent loss is interpreted as the entire loss associated with interaction with the sea surface. In such an approach, the $\chi$ data in Fig. 8, all of which are $O(10)$, would necessarily translate to large and significant estimates of coherent loss, yet incoherent energy loss was in fact small.

The spatial coherence of sound forward scattered from the sea surface was also measured during ASIAEX. These data have been modeled with an approach that utilizes the van Cittert-Zernike theorem in conjunction with the simultaneously measured sea surface spectral wave properties [22]. The concept of a coherence volume, having applications in underwater acoustic imaging and communication, follows from this approach: for the ASIAEX acquisition geometries and surface conditions and for a $20 \mathrm{kHz}$ source at a depth of $25 \mathrm{~m}$ and range 


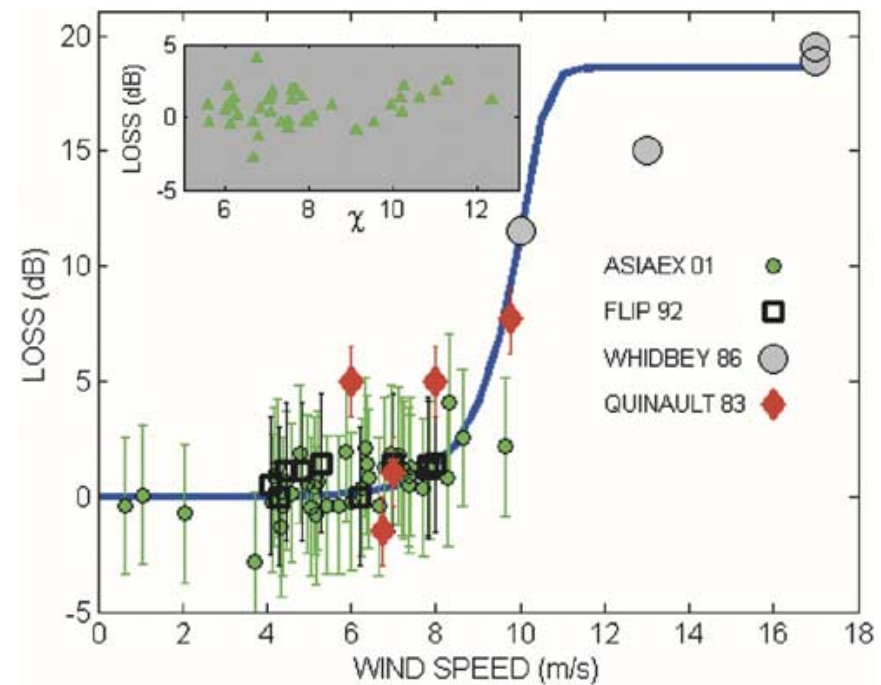

Fig. 8. Estimates of energy loss for a single interaction with the sea surface as a function of wind speed for a nominal sea surface grazing angle of $9^{\circ}$ and frequency $20 \mathrm{kHz}$. Results from ASIAEX and three other experiments are shown (year of the experiment is identified in the legend and additional information given in [20]). Solid, blue curve is a model for energy loss (in [20]) due to attenuation from near-surface bubbles; the model reaches a bound phase (associated with bubble scattering) for wind speeds greater than about 12 $\mathrm{m} / \mathrm{s}$. Shaded plot in upper left corner shows same ASIAEX energy loss data as function of the nondimensional (Rayleigh) parameter $\chi$.

of $0.5 \mathrm{~km}$, a coherence volume exists for receivers between depths of 25 and $50 \mathrm{~m}$. This coherence volume relates to the spatial coherence of the sound field arriving via the surface bounce channel and consists of a vertical layer $0.5 \mathrm{~m}$ thick and $3 \mathrm{~m}$ in each of the two horizontal dimensions or, equivalently, 4-5 $\mathrm{m}^{3}$.

The experimental observations in [23] show that the significant change in sea surface conditions between June 3 and June 5 (see Fig. 5) impacted the broadband (50-1000 Hz) reverberation measurements during this period. Specifically, significantly higher (order $5 \mathrm{~dB}$ ) mean reverberation levels were observed on June 3 , when the rms wave height was $0.1 \mathrm{~m}$ and wind speed was $3 \mathrm{~m} / \mathrm{s}$, than on June 5 , when the rms wave height was $0.34 \mathrm{~m}$ and the wind speed was $9 \mathrm{~m} / \mathrm{s}$. Mechanisms for this change associated with two-way propagation and reflection loss from the sea surface have been proposed [23].

Whether or not the sea surface has a significant effect on the fidelity of geoacoustic inversions will depend on the sea state, the frequency range, and acoustic measure being inverted. We note that the completed inversion studies reported in this volume involving long-range propagation and multiple boundary interaction have not, as is common, addressed this issue per se. Yet, emerging studies [24] suggest, for example, that the aforementioned June 3-to-June 5 change in sea state does impact inversion results. It remains a challenge for future studies involving the ASIAEX ECS data to elucidate and distinguish first order, and higher order, influences of the sea surface on geoacoustic inversion results and their uncertainties.

\section{CONCLUDING REMARKS}

The results summarized here, and presented in greater detail in this issue, can only be regarded as a subset of the results expected to ultimately emerge from the ASIAEX East China Sea program. Taken together, this diverse set of ocean acoustic measurements, spanning a frequency range from $O(10-10000)$ $\mathrm{Hz}$ and representing a large range of temporal and spatial scales, will be brought to bear toward an improved understanding of shallow-water acoustics.

\section{ACKNOWLEDGMENT}

This work was supported by the U.S. Office of Naval Research under Code $321 \mathrm{OA}$ and by sponsoring agencies within China. Primary guidance and sponsorship for ASIAEX East China Sea came from the U.S. Office of Naval Research and significant financial support was also received from sponsoring agencies within China.

\section{REFERENCES}

[1] J. F. Lynch, S. R. Ramp, C.-S. Chiu, T.-Y. Tang, Y.-J. Yang, and J. A. Simmen, "Research highlights from the Asian seas international acoustics experiment in the South China Sea," IEEE J. Oceanic Eng., vol. 29, pp. 1067-1074, Oct. 2004.

[2] S. R. Ramp, C.-S. Chiu, F. L. Bahr, Y. Qi, P. H. Dahl, J. Miller, J. F. Lynch, R. Zhang, and J. Zhou, "The shelf-edge environment in the central East China Sea and its impact on low-frequency acoustic propagation," IEEE J. Oceanic Eng., vol. 29, pp. 1011-1031, Oct. 2004.

[3] J. H. Miller, L. R. Bartek, G. R. Potty, D. Tang, J. Na, and Y. Qi, "Sediments in the East China Sea," IEEE J. Oceanic Eng., vol. 29, pp. 940-951, Oct. 2004.

[4] D. J. Tang, "Fine-scale measurements of sediment roughness and subbottom variability," IEEE J. Oceanic Eng., vol. 29, pp. 929-939, Oct. 2004.

[5] G. W. Caille, P. H. Dahl, Z. Gan, G. Jin, L. Lei, P. H. Rogers, R. C. Spindel, Z. Sun, R. Zang, and J. Zhou, "Overview of the joint China-U.S. Yellow Sea 96 experiment," in Shallow-Water Acoustics, R. Zhang and J. Zhou, Eds. Beijing: China Ocean, 1997, pp. 17-22.

[6] J. Yang, S. Zhou, J.-X. Zhou, and J. F. Lynch, "Internal wave characteristics at the ASIAEX site in the East China Sea," IEEE J. Oceanic Eng., vol. 29, pp. 1054-1060, Oct. 2004.

[7] J. W. Choi and P. H. Dahl, "Mid to high frequency bottom loss in the East China Sea," IEEE J. Oceanic Eng., vol. 29, pp. 980-987, Oct. 2004.

[8] G. R. Potty, J. H. Miller, P. H. Dahl, and C. J. Lazauski, "Geoacoustic inversion results from the ASIAEX East China Sea experiment," IEEE J. Oceanic Eng., vol. 29, pp. 1000-1010, Oct. 2004.

[9] K. Yang, Y. Ma, C. Sun, J. H. Miller, and G. R. Potty, "Multi-step matched field inversion for broadband data from ASIAEX2001," IEEE J. Oceanic Eng., vol. 29, pp. 964-972, Oct. 2004.

[10] Z. Li, R. Zhang, J. Yan, F. Li, and J. Liu, "Geoacoustic inversion by matched-field processing combined with the vertical reflection coefficients and vertical correlation," IEEE J. Oceanic Eng., vol. 29, pp. 973-979, Oct. 2004.

[11] J. Zhou, X.-Z. Zhang, P. H. Rogers, J. A. Simmen, P. H. Dahl, G. Jin, and Z. Peng, "Reverberation vertical coherence and seabottom geoacoustic inversion in shallow water," IEEE J. Oceanic Eng., vol. 29, pp. 988-999, Oct. 2004

[12] Z. Peng, J.-X. Zhou, P. H. Dahl, and R. Zhang, "Seabed acoustic parameters from dispersion analysis and transmission loss in the East China Sea," IEEE J. Oceanic Eng., vol. 29, pp. 1038-1045, Oct. 2004.

[13] H. L. Ge, H. F. Zhao, X. Y. Gong, and E. C. Shang, "Bottom reflection phase shift estimation from ASIAEX data," IEEE J. Oceanic Eng., vol. 29, pp. 1045-1049, Oct. 2004.

[14] C.-F. Huang and W. S. Hodgkiss, "Matched field geoacoustic inversion of low frequency source tow data from the ASIAEX East China Sea experiment," IEEE J. Oceanic Eng., vol. 29, pp. 952-963, Oct. 2004.

[15] D. Tang, "Estimating shallow water bottom geo-acoustic parameters using ambient noise," in Impact of Littoral Environmental Variability on Acoustic Predictions and Sonar Performance, N. G. Pace and F. B. Jensen, Eds. Norwell, MA: Kluwer, 2002, pp. 147-154.

[16] D. M. F. Chapman, "What are we inverting for?," in Inverse Problems in Underwater Acoustics, M. I. Taroudakis and G. N. Makrakis, Eds. New York: Springer, 2001, pp. 1-14. 
[17] N. R. Chapman, S. Chin-Bing, D. King, and R. B. Evans, "Benchmarking geoacoustic inversion methods for range-dependent waveguides," IEEE J. Oceanic Eng., vol. 28, no. July, pp. 320-330, 2003.

[18] R. Zhang, Z. Li, J. Yan, Z. Peng, and F. Li, "Broadband matched-field source localization in the East China Sea," IEEE J. Oceanic Eng., vol. 29, pp. 1049-1054, Oct. 2004.

[19] D. Tang, "Environmental measurements and mid-frequency backscatter in shallow water," in Proc. 144th Meeting Acoustical Society of America, vol. 112, 2002, p. 2361.

[20] P. H. Dahl, "The sea surface bounce channel: Bubble-mediated energy loss and time/angle spreading," in Proc. Amer. Institute of Physics Conf., M. B. Porter, M. Siderius, and W. A. Kuperman, Eds. New York, 2004, pp. 194-204.

[21] - "The contribution of bubbles to high-frequency sea surface backscatter: A 24-h time series of field measurements," J. Acoust. Soc. Amer., vol. 113, no. 2, pp. 769-780, 2003.

[22] - "Forward scattering from the sea surface and the van Cittert-Zernike theorm," J. Acoust. Soc. Amer, vol. 115, no. 2, pp. 589-599, 2004

[23] F. Li, J. Liu, and R. Zhang, "A model/data comparison for shallow water reverberation," IEEE J. Oceanic Eng., vol. 29, pp. 1060-1066, Oct. 2004.

[24] J.-X. Zhou, X.-Z. Zhang, P. H. Dahl, and J. A. Simmen, "Sea surface effects on reverberation vertical coherence and inverted bottom acoustic parameters," in Proc. 147th Meeting Acoustical Society of America, vol. 115,2004, p. 2550

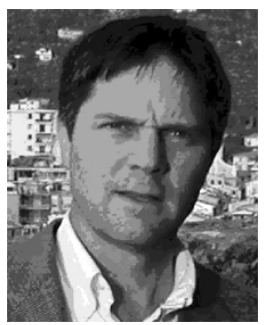

Peter H. Dahl received the Ph.D. degree in ocean engineering from the Massachusetts Institute of Technology, Cambridge/Woods Hole Oceanographic Institution, Woods Hole, MA, Joint Program in Oceanography and Oceanographic Engineering in 1989.

He currently is a Principal Engineer at the Applied Physics Laboratory, University of Washington, Seattle, where he has been since 1989, and conducts experimental and theoretical research in underwater acoustics. He also is a Research Associate Professor in the Mechanical Engineering Department, University of Washington. In 2002, he was a Guest Professor with the Department of Physics, University of Bergen, Norway.

Dr. Dahl served as an Associate Editor for the IEEE JOURNAL OF OCEANIC ENGINEERING from 1997 to 2003 and has served as Guest Editor for this Special Issue on Asian Marginal Seas. He is a Fellow of the Acoustical Society of America (ASA) and currently is Chair of the ASA Technical Committee on Underwater Acoustics. He was the U.S. Chief Scientist for ASIAEX East China Sea.

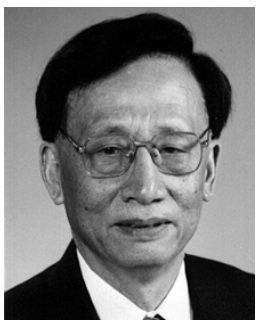

Renhe Zhang was born in Chongqing, China. He graduated from the Department of Physics, Beijing University, Beijing, China, in 1958.

From 1990 to 2000, he was the Director of the National Laboratory of Acoustics at the Chinese Academy of Sciences (CAS), Beijing, China. He is now an Academician at Institute of Acoustics, CAS.

Prof. Zhang is a Chairman of the Western Pacific Commission for Acoustics and a Member of International Acoustic Commission. He has received Zhu Kezheng, Rao Yutai, Guanghua, and Heliang Heli awards for contributions to ocean acoustics in China.

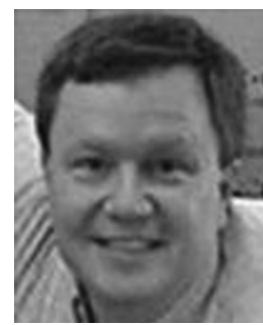

James H. Miller (S'83-M'87) received the B.S. degree in electrical engineering from Worcester Polytechnic Institute, Worcester MA, in 1979, the M.S. degree in electrical engineering from Stanford University, Stanford, CA, in 1981, and the Ph.D. degree in oceanographic engineering from the Massachusetts Institute of Technology, Cambridge/Woods Hole Oceanographic Institution, Woods Hole, MA, joint program in 1987.

He was a Member of the Faculty, Department of Electrical and Computer Engineering, Naval Postgraduate School (NPS), Monterey, CA, from 1987 to 1995. Since 1995 , he has been a Member of the Faculty, Department of Ocean Engineering, University of Rhode Island (URI), Narragansett, where he holds the rank of Professor. He is a Founder of FarSounder, Inc., a startup company that develops forward-looking sonar for vessels, underwater vehicles, and divers. He has authored more than 100 publications in the areas of acoustical oceanography, signal processing, and marine bioacoustics. He has served as Associate Editor for Underwater Sound for the Journal of the Acoustical Society of America, responsible for scattering, inverse methods, and fish acoustics.

Dr. Miller was elected a Fellow of the Acoustical Society of America in 2003 and is a Member of Sigma Xi, Tau Beta Pi, Eta Kappa Nu, the Acoustical Society of America, and the Marine Technology Society. From 2001 to 2003, he was a Member of the National Academy of Sciences Panel on Noise in the Ocean. He serves on the National Marine Fisheries Service Panel on Acoustic Criteria for Marine Mammals. He also serves on the Marine Mammal Commission Subcommittee on the Impacts of Acoustics on Marine Mammals. He received the NPS Menneken Faculty Award for Excellence in Scientific Research and the URI Marshall Award for Faculty Excellence in Engineering in 1993 and 1999, respectively.

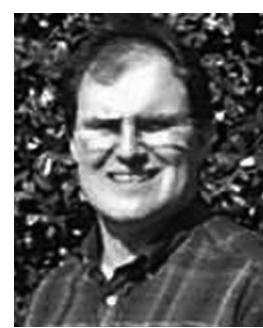

Louis R. Bartek received the B.S. degree from Pennsylvania State University, State College, and the $\mathrm{Ph} . \mathrm{D}$. degree from Rice University, Houston, TX, both in geology.

$\mathrm{He}$ currently is an Associate Professor in the Department of Geological Sciences, University of North Carolina, Chapel Hill. His research interests include the impact of climatic change (i.e., sea level, sediment supply) on the geologic record of continental margins, establishing stochastic models of spatial distribution of physical attributes on continental margins subjected to various environmental boundary conditions, and improving understanding of proximal record of climate change on Antarctic continental margin with proxy records from the deep sea.

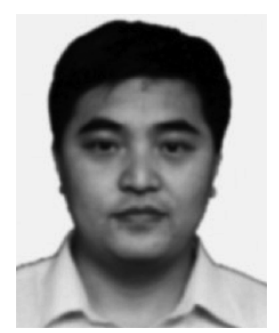

Zhaohui Peng received the B.S. degree in civil engineering in 1993 and the M.S. and Ph.D. degrees in solid mechanics in 1996 and 1998, respectively, all from Harbin Engineering University, Harbin, China.

He was a Postdoctoral Fellow with the Institute of Acoustics, Chinese Academy of Sciences, Beijing, China, in 1998. He was a Postdoctoral Fellow with the Georgia Institute of Technology, Atlanta, in 2002. Presently, he is an Associate Professor with the Institute of Acoustics, Chinese Academy of Sciences.

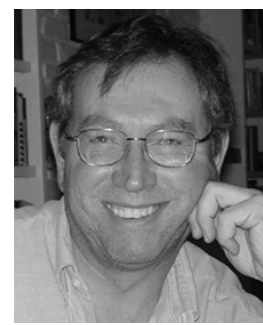

Steven R. Ramp received the M.S. degree in physical oceanography from the University of Washington, Seattle, in 1976, and the Ph.D. degree in physical oceanography from the University of Rhode Island, Narragansett, in 1986.

Since 1986, he has been with the U.S. Navy as a Professor at the Naval Postgraduate School, Monterey, CA, and a Program Officer at the Office of Naval Research, Arlington, VA. Prior to this, he spent time at the National Marine Fisheries Service, Woods Hole, MA. His research specialty is ocean observations from both ships and oceanographic moorings, and he has organized major expeditions to the Japan Sea, East China Sea, and South China Sea. He was the International Scientific Coordinator for the Asian Seas International Acoustics Experiment (ASIAEX). 


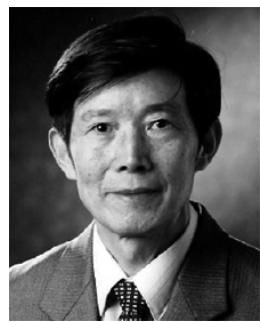

Ji-Xun Zhou graduated from the Physics Department, Nanjing University, Nanjing, China, with a five-year degree in 1963 and graduated from the Graduate School of the Chinese Academy of Sciences (CAS), Beijing, China, associated with the Institute of Acoustics (IOA), for his graduate studies.

He started his research on shallow-water acoustics with the IOA and was promoted to Full Professor. Since April 1989, he was officially appointed as a Visiting Professor and, later, as a Principal Research Scientist with the Georgia Institute of Technology (Georgia Tech), Atlanta, where he has been advising postdoctoral fellows and $\mathrm{Ph}$.D./M.S. students and visiting scholars. In recent years, his main areas of research have included acoustic interactions with internal waves, sea-bottom geoacoustic inversion, and reverberation and signal spatial coherence in shallow water.

Dr. Zhou was twice awarded the China Natural Science Award (both were 2nd place), as a coauthor, in 1982 and 1989, due to his contributions to shallow-water acoustics.

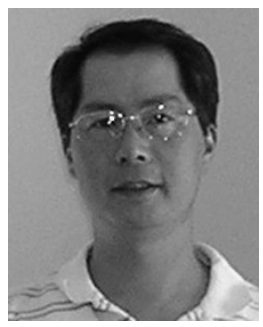

Ching-Sang Chiu received the Ph.D. degree from the Massachusetts Institute of Technology/Woods Hole Oceanographic Institution, Woods Hole, MA (MIT-WHOI) joint program in 1985.

$\mathrm{He}$ is a Professor of oceanography with the Naval Postgraduate School. His research specialties include ocean acoustics, acoustical oceanography, and coastal ocean processes and their influences on acoustics prediction. He has authored or coauthored more than 40 refereed publications in those subject areas.

Dr. Chiu is a Fellow of the Acoustical Society of America and Editor-in-Chief of the Journal of Computational Acoustics.

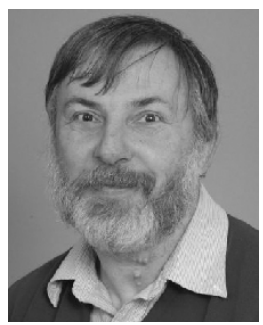

James F. Lynch (M'96-SM'03) was born in Jersey City, NJ, on June 3, 1950. He received the B.S. degree in physics from Stevens Institute of Technology, Hoboken, NJ, in 1972 and the Ph.D. degree in physics from the University of Texas, Austin, in 1978.

He was with the Applied Research Laboratories, University of Texas at Austin (ARL/UT) from 1978 to 1981 , after which he joined the scientific staff at the Woods Hole Oceanographic Institution (WHOI), Woods Hole, MA. He has been with WHOI since then and currently holds the position of Senior Scientist in the Applied Ocean Physics and Engineering Department. His research specialty areas are ocean acoustics and acoustical oceanography, but he also greatly enjoys occasional forays into physical oceanography, marine geology, and marine biology.

Dr. Lynch is a Fellow of the Acoustical Society of America and Editor-inChief of the IEEE JOURNAL OF OCEANIC ENGINEERING.

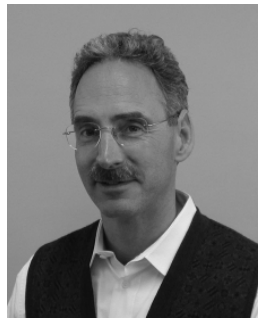

Jeffrey A. Simmen received the Ph.D. degree in applied mathematics from the California Institute of Technology, Pasadena, in 1984.

He was with the Center for Naval Analyzes (CNA), Alexandria, VA, on operations research and tactical development for submarine and antisubmarine warfare operations for the following five years. While with the CNA, he spent two years on assignment in Italy at the submarine command COMSUBGRUEIGHT. In 1989, joined the Naval Postgraduate School, Monterey, CA, and the University of California, Santa Cruz, respectively, for the next few years, where he taught and conducted research in fluid dynamics and ocean acoustics. In 1993, he joined the Office of Naval Research, Washington, DC, where he managed a basic and applied research program in ocean acoustics. In 2003, he became the seventh Director of the Applied Physics Laboratory, University of Washington, Seattle. His research interests include sound propagation through internal waves and fluctuations in high-frequency acoustics.

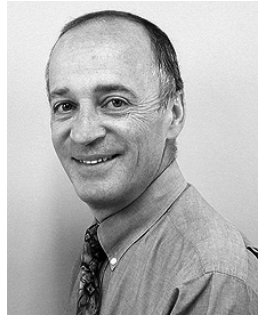

Robert C. Spindel received the B.E. degree in electrical engineering from The Cooper Union, New York, NY, in 1965 and the M.S., M. Phil., and Ph.D. degrees from Yale University, New Haven, CT, in 1966, 1968, and 1971, respectively.

During 1971, he was a Postdoctoral Research Fellow at the Woods Hole Oceanographic Institution, Woods Hole, MA, where he joined the staff the same year. In 1982, he was appointed Chair of the Ocean Engineering Department. In 1987, he joined the University of Washington, Seattle, WA, where he served as the Director of the Applied Physics Laboratory until 2003. He is a Professor of electrical engineering and oceanography.

Dr. Spindel is a Fellow of the Acoustical Society of America as well as of the Marine Technology Society, where he was a President from 1993 to 1994 . He has served on the administrative committee of the IEEE Oceanic Engineering Society and has been an Associate Editor of the IEEE JOURNAL OF OCEANIC ENGINEERING for many years. 